Canadian

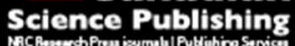

Canadian Journal of Microbiology Revue canadienne de de microbiologie

\title{
Bacterial community composition and fermentation in the rumen of Xinjiang brown cattle (Bos taurus), Tarim red deer (Cervus elaphus yarkandensis), and Karakul sheep (Ovis aries)
}

\begin{tabular}{|r|l|}
\hline Journal: & Canadian Journal of Microbiology \\
\hline Manuscript ID & cjm-2016-0596.R1 \\
\hline Danuscript Type: & Article \\
\hline Complete List of Authors: & $\begin{array}{l}\text { Qian, Wenxi; College of Animal Science and Technology, Gansu Agricultural } \\
\text { University } \\
\text { Li, Zhipeng; Chinese Academy of Agricultural Sciences, Institute of Special } \\
\text { Wild Economic Animal and Plant Science } \\
\text { Ao, Weiping; College of Animal Science ,Tarim University } \\
\text { Zhao, Guangyong; China Agricultural University } \\
\text { Li, Guangyu; Chinese Academy of Agricultural Sciences, Institute of Special } \\
\text { Wild Economic Animal and Plant Science } \\
\text { Wu, Jianping; College of Animal Science and Technology, Gansu } \\
\text { Agricultural University }\end{array}$ \\
\hline Keyword: & \begin{tabular}{l} 
ruminants, microbiota, Prevotella spp., fermentation products \\
\hline
\end{tabular} \\
\hline
\end{tabular}

\section{SCHOLARONE \\ Manuscripts}




\section{Bacterial community composition and fermentation in the rumen of Xinjiang}

brown cattle (Bos taurus), Tarim red deer (Cervus elaphus yarkandensis), and

\section{Karakul sheep (Ovis aries)}

Wenxi Qian ${ }^{1,3 \#}$, ZhiPeng $\mathrm{Li}^{2 \#}$, Weiping $\mathrm{Ao}^{3}$, Guangyong Zhao ${ }^{4}$, Guangyu $\mathrm{Li}^{2 *}$, JianPing $\mathrm{Wu}^{1 *}$

${ }^{1}$ College of Animal Science and Technology, Gansu Agricultural University, Lanzhou 730070, China

${ }^{2}$ Institute of Special Animal and Plant Sciences, Chinese Academy of Agricultural Sciences, Changchun, 130112, China

${ }^{3}$ College of Animal Science, Tarim University, Alar, 843300, China

${ }^{4}$ College of Animal Science and Technology, China Agricultural University, Beijing, 100083, China

*Corresponding authors:

Guangyu Li, Email: tcslgy@126.com, Tel: +8643181919515, Fax: +86 43181919800, No 4899, Juye Street, Changchun, Jilin Province, 130112, China.

JianPing Wu, E-mail: jianpingwujpwgsau@163.com, Tel: +869317631492, Fax: +869317668010, No. 1, Yingmen village, Lanzhou, Gansu Province, 73007, China.

\# These authors contributed equally to this study.

\section{Email addresses:}

Wenxi Qian: qianwenxizj@163.com

Zhipeng Li: zhplicaas@163.com

Weiping Ao: awpdky@126.com

Guangyong Zhao: zhaogy@cau.edu.cn

Guangyu Li:tcslgy@126.com

JianPing Wu: jianpingwujpwgsau@163.com 


\section{Abstract}

The rumen microbiota plays a major role in the metabolism and absorption of indigestible food sources. Xinjiang brown cattle (Bos taurus), Tarim red deer (Cervus elaphus yarkandensis), and Karakul sheep (Ovis aries) are important ruminant species for animal husbandry in the Tarim Basin. However, the microbiota and rumen fermentation of these animals are poorly understood. Here, we apply high-throughput sequencing to examine the bacterial community in the rumen of cattle, red deer and sheep and measured rumen fermentation products. Overall, 548,218 high-quality sequences were obtained and then classified into 6,034 operational taxonomic units (OTUs). Prevotella spp., Succiniclasticum spp., and unclassified bacteria within the families Succinivibrionaceae, Lachnospiraceae, and Veillonellaceae were the dominant bacteria in the rumen across the three hosts. Principal coordinate analysis (PCoA) identified significant differences in the bacterial communities across the three hosts. Pseudobutyrivibrio spp., Oscillospira spp., and Prevotella spp. were more prevalent in the rumen of the cattle, red deer and sheep, respectively. Among the three hosts, the red deer rumen had the greatest amounts of acetate and butyrate and the lowest $\mathrm{pH}$ value. These results showed that Prevotella spp. are the dominant bacteria in the rumen of the cattle, red deer and sheep, providing new insight into the rumen fermentation of ruminants distributed in the Tarim Basin.

Key words: ruminants; microbiota; Prevotella spp.; fermentation products 


\section{Introduction}

The suborder Ruminantia, which includes the families Cervidae and Bovidae, is the most important group of large terrestrial herbivorous mammals (Fernández and Vrba 2005). Among these mammals, ruminants are particularly interesting because they are ecologically and physiologically diverse and have the ability to ingest large amounts of fibrous plants (Clauss et al. 2010). However, ruminants do not produce fiber-degrading enzymes to digest fibrous plant materials; instead, they depend on a diverse and dense array of microorganisms, including bacteria, fungi, archaea and protozoa (Wright and Klieve 2011). Among these microorganisms, bacteria play a major role in degrading plant biomass, and the subsequent rumen fermentation produces ammonia and volatile fatty acids (VFAs), such as acetate, propionate and butyrate (Puniya et al. 2015). These end products supply the host with essential nutrients and metabolic energy (i.e., VFAs) (Bergman 1990). Therefore, the rumen microbiota directly affects the host's physiology, health and production.

Xinjiang brown cattle (Bos taurus), Tarim red deer (Cervus elaphus yarkandensis), and Karakul sheep (Ovis aries) are important ruminant species in the animal husbandry industry of the Xinjiang Uygur Autonomous Region, China. These animals are distributed along the southeastern edge of the Tarim Basin, which is surrounded by the Taklimakan Desert, and they have adapted to the extremely harsh living conditions by incorporating Phragmites communis and Populus diversifolia as the main forage in their diet (Qiao et al. 2006). However, the rumen microbiota of these animals fed typical diets has not been characterized to date. Red deer are 
considered an endangered species by the International Union for the Conservation of Nature (IUCN) (Halk et al. 2004), and examining the bacterial community could improve our understanding of the rumen ecology of endangered species and provide valuable information for species conservation strategies.

The host-associated microbiota is significantly affected by heritable factors, such as host genetics (Goodrich et al. 2014), environmental factors such as the diet composition (Henderson et al. 2015; Smith et al. 2015), and the geographic location (Moeller et al. 2013). Therefore, the rumen microbiota may differ among Xinjiang brown cattle, Karakul sheep and Tarim red deer. In addition, previous studies have demonstrated that diet plays a role in shaping the gastrointestinal microbiota (Carmody et al. 2015). Pérez-Barberia et al. (2004) revealed the rate of evolution of fiber digestibility to be related to climatically driven environmental changes over the past several million years. Moeller et al. (2013) showed that geographic isolation among host species promoted evolutionary differentiation in the gut bacterial community of great apes. Considering the main forages of the three studied hosts, including Phragmites communis and Populus diversifolia (Qiao et al. 2006), examining rumen fermentation will improve our understanding the roles of the bacterial community.

In the present study, we aimed to investigate the bacterial community of the rumens of Xinjiang brown cattle, Karakul sheep and Tarim red deer distributed in a desert region, and examine and compare the rumen fermentation parameters across the three hosts. 


\section{Materials and methods}

\section{Animals and sample collection}

Three rumen-cannulated brown cattle [mean body weight $(\mathrm{MBW})=400 \pm 5.5$ $\mathrm{kg}$ ], three Tarim red deer $(\mathrm{MBW}=140 \pm 1.6 \mathrm{~kg})$, and three karakul sheep $(\mathrm{MBW}=36$ $\pm 1.2 \mathrm{~kg}$ ) were used in this study and maintained at the experimental animal center of Tarim University. All of the animals were assigned to individual pens under the following conditions: $30^{\circ} \mathrm{C}$ mean temperature and $55 \mathrm{~mm}$ annual rainfall, from August to September of 2015. The animals were fed twice each day at 8:00 AM and 7:00 PM and provided free access to water. The brown cattle, Tarim red deer and Karakul sheep were fed the same typical diet of forage and concentrate (forage:concentrate $=70: 30$, dry matter basis, Table 1) for 20 days. All of the animal procedures were approved and authorized by the animal ethics committee of Tarim University. Over the last three days of the feeding period, the whole rumen contents were collected at $2 \mathrm{~h}$ after the morning feeding. The rumen samples were stored at $-80^{\circ} \mathrm{C}$ for further analysis.

\section{DNA extraction, sequencing and bioinformatics analyses}

The total genomic DNA of the rumen microorganisms was extracted from the whole rumen contents of each animal using the QIAamp DNA Stool Mini Kit (QIAGEN, Valencia, CA, USA) according to the manufacturer's instructions. The universal primers 515F (5'-GTGCCAGCMGCCGCGGTAA-3') and 806R (5'-GGACTACHVGGGTWTCTAAT-3) were used to amplify the V4 region of the bacterial 16S rRNA gene (Caporaso et al. 2012). The amplicons were quantified using 
a QuantiFluor ${ }^{\circledR}-\mathrm{P}$ Fluorometer (Promega, CA, USA) and sequenced on an Illumina HiSeq 2500 platform to generate 250 bp paired-end reads.

The sequences were processed and analyzed using QIIME ver. 1.7.0 (Caporaso et al. 2010). Chimeric sequences were detected and removed using the software Uchime (Edgar et al. 2011). The remaining sequences were classified into operational taxonomic units (OTUs) based on a sequence identity of $97 \%$ at the species level using UPARSE (Edgar 2013). The representative sequences of each OTU were searched against the GreenGene database using the Ribosomal Database Project (RDP) classifier with a 0.80 confidence threshold (DeSantis et al. 2006; Wang et al. 2007). Good's coverage estimator and the Shannon-Wiener, Simpson, and Chao 1 alpha diversity indices were calculated for all samples using QIIME ver. 1.7.0 (Caporaso et al. 2010). To compare the bacterial communities in the rumen across all three hosts, the unweighted UniFrac distances (which examine the presence and absence of bacterial lineages) and weighted UniFrac distances (which consider the relative abundance of bacterial lineages) were used in the principal coordinate analysis (PCoA) (Lozupone et al. 2011). The sequences were deposited in the Sequence Read Archive under accession number SRP090262.

\section{Measurement of ruminal fermentation parameters}

The $\mathrm{pH}$ value of the ruminal contents was immediately determined using a $\mathrm{pH}$ meter (FE20, Mettler-Toledo, Switzerland). The amount of ammonia was measured according to the phenol-sodium hypochlorite method as previously described (Li et al. 2015). The concentrations of VFAs in the rumen were analyzed via gas 
chromatography (TP-2060F, Beijing BeifenTianpu Instrument Technology Co. Ltd., Beijing, China) with a flame ionization detector and a PEG-20M $\mathrm{H}_{3} \mathrm{PO}_{4}$ glass column. The flow rate of the carrier gas was $30 \mathrm{ml} / \mathrm{min}$ with the column temperature at $120^{\circ} \mathrm{C}$, and the detector temperature was $220^{\circ} \mathrm{C}$.

\section{Statistical analysis}

Values for the bacterial composition and fermentation parameters were expressed as the mean \pm S.D. (standard deviation). Multiple sample comparisons were performed using a one-way analysis of variance (ANOVA). $P<0.05$ was regarded as a significant difference.

\section{Results}

\section{Summary of the sequencing data}

A total of 548,218 high-quality sequences were obtained for the bacterial $16 \mathrm{~S}$ rRNA gene. Based on a $97 \%$ sequence identity, these bacterial sequences were assigned to 6,034 OTUs (Table 2). Good's coverage estimate, which reflects sequencing efforts, showed that $98.0 \pm 0.1$ (Mean \pm S.D.) $\%$ of the total bacterial species were captured in any given sample. The comparisons across all three hosts showed that the richness (Chao1) and diversity (Shannon) indices were not significantly different among the three hosts $(P>0.05)$.

\section{Bacterial composition in the rumen of three hosts}

Overall, 53 phyla were identified in the rumen across the three hosts, and they were dominated by Bacteroidetes (cattle $=42.7 \pm 3.6 \%$, red deer $=36.2 \pm 3.2 \%$, and sheep $=46.6 \pm 6.6 \%)$, Proteobacteria $($ cattle $=19.6 \pm 2.0 \%$, red deer $=24.7 \pm 3.3 \%$, 
and sheep $=23.2 \pm 5.7 \%)$, and Firmicutes $($ cattle $=20.4 \pm 2.7 \%$, red deer $=17.0 \pm$ $2.8 \%$, and sheep $=15.5 \pm 2.6 \%)($ Figure 1A).

At the genus level, Prevotella spp. $(26.8 \pm 3.3 \%)$ were the most dominant bacteria in the rumen of the cattle, and it was followed by Succiniclasticum spp. $(3.5 \pm$ $1.2 \%)$, unclassified bacteria within the families Lachnospiraceae $(2.0 \pm 0.3 \%)$ and Veillonellaceae $(1.7 \pm 0.7 \%)$, and Butyrivibrio spp. $(1.3 \pm 0.4 \%)$. In the rumen of the red deer, Prevotella spp. $(23.1 \pm 3.5 \%)$ were the dominant bacteria, followed by Succiniclasticum spp. $(2.8 \pm 1.2 \%)$ and unclassified bacteria within the families Succinivibrionaceae $(2.4 \pm 0.8 \%)$, Lachnospiraceae $(1.6 \pm 0.4 \%)$, and Veillonellaceae $(1.6 \pm 0.7 \%)$. In the rumen of the sheep, Prevotella spp. $(34.2 \pm 3.8 \%)$ were the predominant bacteria, followed by Selenomonas spp. $(2.3 \pm 1.5 \%)$ and unclassified bacteria within the families Veillonellaceae $(2.2 \pm 0.5 \%)$, Lachnospiraceae $(1.4 \pm$ 0.4\%), and Succinivibrionaceae $(1.1 \pm 0.03 \%)$ (Figure 1B).

\section{Comparison of the rumen bacterial composition across all three hosts}

The unweighted UniFrac distance (presence/absence of bacterial taxa) showed that the bacterial community composition in the rumen of the cattle, red deer, and sheep was different, and it explained 37.92\% of the variance (Figure 2A). Moreover, the weighted UniFrac distance (based on the presence-absence and the relative abundance of bacterial taxa) for the differences in the bacterial community structure across all three hosts explained $58.46 \%$ of the variance (Figure 2B). We further compared the relative abundance of bacteria in the rumen across the three hosts

(Figure 2C), and found that the abundance of Pseudobutyrivibrio spp. $(0.21 \pm 0.01 \%)$ 
was significantly higher in the rumen of the cattle than the sheep $(0.03 \pm 0.001 \%, P=$ $0.0008)$ and red deer $(0.08 \pm 0.002 \%, P=0.002)$. The proportion of Oscillospira spp. in the rumen of the cattle $(0.06 \pm 0.002 \%, P=0.02)$ and sheep $(0.06 \pm 0.003 \%, P=$ $0.02)$ was significantly lower than that of the red deer $(0.14 \pm 0.02 \%)$. The genus Prevotella was more abundant in the rumen of the sheep $(34.2 \pm 3.8 \%)$ than in the rumen of the red deer $(23.1 \pm 3.5 \%, P=0.03)$, whereas the relative abundance of Streptococcus spp. in the rumen of the sheep $(0.007 \pm 0.004 \%)$ was lower than that in the rumen of the red deer $(0.02 \pm 0.003 \%, P=0.04)$.

\section{Comparison of fermentation parameters among different animal species}

The $\mathrm{pH}$ in the rumen of cattle $(6.09 \pm 0.09)$ and sheep $(6.10 \pm 0.12)$ was significantly higher than that of red deer $(5.94 \pm 0.03, P<0.05)$. The concentration of ammonia in the rumen across the three hosts was not significantly different $(P>0.05)$. The concentrations of acetate $(43.4 \pm 1.4)$ and butyrate $(27.5 \pm 4.7)$ in the rumen of the red deer were significantly higher than those of the cattle (acetate: $38.1 \pm 3.5$; butyrate: $17.0 \pm 3.2$ ) and sheep (acetate: $38.9 \pm 3.6$; butyrate: $23.5 \pm 3.6$ ). The amounts of propionate, isobutyrate and isovalerate in the rumen of the cattle tended to be greater than that in the rumen of the red deer and sheep, whereas the concentration of valerate in the rumen of the sheep tended to be greater than that in the rumen of the cattle and red deer, although the differences were not significant (Figure 3).

\section{Discussion}

In this study, we examined and compared the rumen bacterial community and fermentation parameters in the rumens of Xinjiang brown cattle, Tarim red deer and 
Karakul sheep. The results indicated that Prevotella spp. were the dominant bacteria in the rumen across the three hosts. Moreover, the relative abundance of bacteria and the amounts of fermentation products also differed across the three hosts.

The results presented here indicate that Prevotella spp. are the dominant bacteria in the rumen of the cattle, red deer, and sheep. This result was consistent with the findings for other ruminant species, including Bovinae, Cervidae, Caprinae, Camelidae and Giraffidae (Henderson et al. 2015). Moreover, the predominant bacteria in the rumen of red deer were similar to those in elk, white-tailed deer, roe deer, sika deer, reindeer and moose (Gruninger et al. 2014; Ishaq and Wright 2014; Li et al. 2013; Li et al. 2014; Sundset et al. 2007). This result suggest an effect on rumen microbiota by host genetics (Moeller et al. 2013). Prevotella spp. are a bacterial group that presents genetic and metabolic diversity in rumen microbial communities (Bekele et al. 2010; Purushe et al. 2010). Previous studies demonstrated that Prevotella spp. contained active hemicellulolytic and proteolytic enzymes (Matsui et al. 2000), which played roles in degrading starch, xylan, lignans and pectin (Cotta 1992; Gardner et al. 1995). Additionally, metagenomic analyses in the rumen of Svalbard reindeer and sika deer also suggested that Prevotella spp. plays a potential role in cellulose degradation (Li et al. 2013; Pope et al. 2012). Indeed, Huws et al. (2016) demonstrated that a high abundance of Prevotella spp. was observed during the successional colonization of fresh perennial ryegrass in the rumen of cows, regardless of temporal changes. Taken together, these results suggest the potential roles of Prevotella spp. in the decomposition of plant fiber materials. 
The results also showed that Succiniclasticum spp. were the second most predominant bacteria in the rumen of the cattle and red deer, whereas unclassified bacteria within the families Succinivibrionaceae and Lachnospiraceae were abundant in the rumen across the three hosts. The ecological roles or physiological properties of Succiniclasticum spp. in the rumen are poorly understood because only one isolate has been cultured in vitro. Van Gylswyk (1995) reported that Succiniclasticum ruminis plays a major role in converting succinate to propionate as the sole energy-yielding mechanism. Certain bacterial members within the family Succinivibrionaceae produce succinate as the principal fermentation product, and a number of exogenous sources of hydrogen could stimulate the formation of succinate (Pope et al. 2011; Stackebrandt and Hespell 2006), which was dominant in the rumen of sika deer (Li et al. 2015). Bacteria within the family Lachnospiraceae produced butyrate (Cotta and Forster 2006), which was also dominant in the rumens of moose and various arctic ruminants (Ishaq and Wright 2012; Ishaq and Wright 2014) as well as in the foregut of dromedary camels in Australia (Samsudin et al. 2011). Taken together, these results suggested that these bacteria may contribute to the converting plant materials to propionate and butyrate to meet the host's energy demands under harsh conditions.

The present study also showed a significant difference in the bacterial community composition across the three hosts. The difference among the three hosts was increased with the weighted UniFrac distance (based on presence-absence and relative abundance of bacterial taxa) compared with the unweighted UniFrac distance (presence/absence of bacterial taxa, Figures $\mathbf{2 A}$ and 2B), indicating that the relative 
abundance of certain bacteria contributed to the bacterial community difference. Pseudobutyrivibrio spp., Oscillospira spp., and Prevotella spp. were more prevalent in the rumen of the cattle, red deer and sheep, respectively (Figure 2C). Pseudobutyrivibrio spp. play fibrolytic roles during rumen fermentation because they contain xylanases that randomly cleave the $\beta$-1,4-backbone of the complex plant cell wall polysaccharide xylan (Grilli et al. 2012; Krause et al. 2003). In addition, amylase can be produced by the members of Pseudobutyrivibrio spp. in the rumen (Moon et al. 2008). These results suggested an important role of these bacteria during rumen fermentation in cattle. Oscillospira spp. are broadly observed in various rumen ecosystems, such as those of cattle, sheep and reindeer, and the level is dependent on the dietary composition (Mackie et al. 2003). However, a pure isolate within Oscillospira spp. has never been cultured (Konikoff and Gophna 2016). Previous studies showed that members of the Oscillospira genus were enriched in lean subjects and unlikely to represent complex fiber degraders in the human gut (David et al. 2014; Goodrich et al. 2014). Moreover, a previous study demonstrated that venison has a high protein and low fat content (Asano et al. 2005), indicating that Oscillospira spp. may play a role in rumen fermentation and host metabolism.

In the present study, we observed that the amount of acetate in the rumen of the red deer was significantly greater than that of the cattle and sheep, whereas the $\mathrm{pH}$ value in the rumen of the red deer was significantly lower than that of the cattle and sheep (Figure 3). Moreover, the concentrations of isobutyrate and isovalerate in the rumen of the studied cattle tended to be greater than that in the rumen of the sheep 
and red deer (Figure 3). Isobutyrate and isovalerate are degradation products derived from branched-chain amino acids, such as leucine, valine, and isoleucine (Allison 1978). Thus, our results indicated an increased level of protein degradation in the rumen of the cattle. The changed amounts of isobutyrate and isovalerate may be related to particle retention in the rumen, which is associated with the body of the ruminant and represents a heritable trait (Goopy et al. 2014). Asano et al. (2005) reported that the rate of ruminal passage was higher in sika deer than in cattle. The longer particle passage rate of the particulate and liquid fractions resulted in changes to the protozoal composition because the generation of protozoa was observed to adapt to changes in the substrates as well as the turnover rate in the rumen (Sylvester et al. 2009), thereby contributing to the increased degradation of amino acids from protozoa (Newbold et al. 2015). In future studies, the relationship between protozoa and nutrient digestibility in the rumen across the three hosts must be further documented.

In the present study, we demonstrated that Prevotella spp. were the dominant bacteria in the rumen of the studied cattle, red deer, and sheep. In addition, the amounts of rumen fermentation products suggested that the rumen metabolism across the three hosts differed, which may have been caused by changes in the rumen microbiota. These results expand our knowledge of the rumen ecology of ruminants distributed in the Tarim Basin, which presents harsh environmental conditions.

\section{Acknowledgements}

This study is supported by the Natural Science Foundation of China (NSFC) (Grant 
No. 31260569 and 31460610), also supported by the Joint training program for young teachers of China Agricultural University and Tarim University(Grant No. ZNTDLH1502) 


\section{References}

Allison, M.J. 1978. Production of branched-chain volatile fatty acids by certain anaerobic bacteria. Appl. Environ. Microbiol. 35(5): 872-877.

Asano, S., Ikeda, S., Kurokawa, Y., Kanda, S., and Itabashi, H. 2005. Comparison of digestibility, passage rate and rumen fermentation between sika deer (Cervus Nippon) and cattle fed alfalfa hay cubes. Anim. Sci. J. 76(5): 447-451. doi:10.1111/j.1740-0929.2005.00289.x.

Bekele, A.Z., Koike, S., and Kobayashi, Y. 2010. Genetic diversity and diet specificity of ruminal Prevotella revealed by $16 \mathrm{~S}$ rRNA gene-based analysis. FEMS Microbiol. Lett. 305(1): 49-57. doi:10.1111/j.1574-6968.2010.01911.x.

Bergman, E.N. 1990. Energy contributions of volatile fatty acids from the gastrointestinal tract in various species. Physiol. Rev. 70(2): 567-590.

Caporaso, J.G., Kuczynski, J., Stombaugh, J., Bittinger, K., Bushman, F.D., Costello, E.K., Fierer, N., Peña, A.G., Goodrich, J.K., and Gordon, J.I., Huttley, G.A., Kelley, S.T., Knights, D., Koenig, J.E., Ley, R.E., Lozupone, C.A., McDonald, D., Muegge, B.D., Pirrung, M., and Reeder, J. 2010. QIIME allows analysis of high-throughput community sequencing data. Nat. Methods 7(5): 335-336. doi:10.1038/nmeth.f.303.

Caporaso, J.G., Lauber, C.L., Walters, W.A., Berg-Lyons, D., Huntley, J., Fierer, N., Owens, S.M., Betley, J., Fraser, L., Bauer, M., Gormley, N., Gilbert, J.A., Smith, G., and Knight, R. 2012. Ultra-high-throughput microbial community analysis on the Illumina HiSeq and MiSeq platforms. ISME J. 6(8): 1621-1624. 
doi:10.1038/ismej.2012.8.

Carmody, R.N., Gerber, G.K., Luevano, J.M., Jr., Gatti, D.M., Somes, L., Svenson, K.L., and Turnbaugh, P.J. 2015. Diet dominates host genotype in shaping the murine gut microbiota. Cell Host Microbe 17(1): 72-84. doi:10.1016/j.chom.2014.11.010.

Clauss, M., Hume, I.D., and Hummel, J. 2010. Evolutionary adaptations of ruminants and their potential relevance for modern production systems. Animal 4(7): 979-992. doi:10.1017/S1751731110000388.

Cotta, M., and Forster, R. 2006. The family Lachnospiraceae, including the Genera Butyrivibrio, Lachnospira and Roseburia. In The Prokaryotes. Edited by M. Dworkin, S. Falkow, E. Rosenberg, K.-H. Schleifer and E. Stackebrandt. Springer US, New York. pp. 1002-1021.

Cotta, M.A. 1992. Interaction of ruminal bacteria in the production and utilization of maltooligosaccharides from starch. Appl. Environ. Microbiol. 58(1): 48 - 54.

David, L.A., Maurice, C.F., Carmody, R.N., Gootenberg, D.B., Button, J.E., Wolfe, B.E., Ling, A.V., Devlin, A.S., Varma, Y., Fischbach, M.A., Biddinger, S.B., Dutton, R.J., and Turnbaugh, P.J. 2014. Diet rapidly and reproducibly alters the human gut microbiome. Nature 505(7484): 559-563. doi:10.1038/nature 12820 .

DeSantis, T.Z., Hugenholtz, P., Larsen, N., Rojas, M., Brodie, E.L., Keller, K., Huber, T., Dalevi, D., Hu, P., and Andersen, G.L. 2006. Greengenes, a chimera-checked 16S rRNA gene database and workbench compatible with 
ARB. Appl. Environ. Microbiol. 72(7): 5069-5072. doi:10.1128/AEM.03006-05.

Edgar, R.C. 2013. UPARSE: highly accurate OTU sequences from microbial amplicon reads. Nat. Methods 10(10): 996-998. doi:10.1038/nmeth.2604.

Edgar, R.C., Haas, B.J., Clemente, J.C., Quince, C., and Knight, R. 2011. UCHIME improves sensitivity and speed of chimera detection. BioInformatics 27(16): 2194-2200. doi:10.1093/bioinformatics/btr381.

Fernández, M.F., and Vrba, E.S. 2005. A complete estimate of the phylogenetic relationships in Ruminantia: a dated species-level supertree of the extant ruminants. Biol. Rev. 80(2): 269-302. doi:10.1017/S1464793104006670.

Gardner, R.G., Wells, J.E., Russell, J.B., and Wilson, D.B. 1995. The cellular location of Prevotella ruminicola beta-1,4-D-endoglucanase and its occurrence in other strains of ruminal bacteria. Appl. Environ. Microbiol. 61(9): 3288-3292.

Goodrich, J.K., Waters, J.L., Poole, A.C., Sutter, J.L., Koren, O., Blekhman, R., Beaumont, M., Van Treuren, W., Knight, R., Bell, J.T., Spector, T.D., Clark, A.G., and Ley, R.E. 2014. Human genetics shape the gut microbiome. Cell 159(4): 789-799. doi:10.1016/j.cell.2014.09.053.

Goopy, J.P., Donaldson, A., Hegarty, R., Vercoe, P.E., Haynes, F., Barnett, M., and Oddy, V.H. 2014. Low-methane yield sheep have smaller rumens and shorter rumen retention time. Br. J. Nutr. 111(4): 578-585. doi:10.1017/S0007114513002936.

Grilli, D.J., Cerón, M.E., Paez, S., Egea, V., Schnittger, L., Cravero, S., Escudero, 
M.S., Allegretti, L., and Arenas, G.N. 2013. Isolation of Pseudobutyrivibrio ruminis and Pseudobutyrivibrio xylanivorans from rumen of Creole goats fed native forage diet. Folia Microbiol. (Praha) 58: 367-373 doi:10.1007/s12223-012-0219-1.

Gruninger, R.J., Sensen, C.W., McAllister, T.A., and Forster, R.J. 2014. Diversity of rumen bacteria in Canadian cervids. PLOS ONE 9(2): e89682. doi:10.1371/journal.pone.0089682.

Halk, M., Abliz, O., Tumur, A., Zhu, F., Mosa, A., and Ohtaishi, N. 2004. The present living status of Tarim red deer(Cervus elaphus yarkandensis) and its protective countermeasures. Shou lei xue bao =. Acta Theriol. Sin. 24(4): 329-332.

Henderson, G., Cox, F., Ganesh, S., Jonker, A., Young, W., Global Rumen Census Collaborators, and Janssen, P.H. 2015. Rumen microbial community composition varies with diet and host, but a core microbiome is found across a wide geographical range. Sci. Rep. 5: 14567. doi:10.1038/srep14567.

Huws, S.A., Edwards, J.E., Creevey, C.J., Rees Stevens, P., Lin, W., Girdwood, S.E., Pachebat, J.A., and Kingston-Smith, A.H. 2016. Temporal dynamics of the metabolically active rumen bacteria colonizing fresh perennial ryegrass. FEMS Microbiol. Ecol. 92(1). doi:10.1093/femsec/fiv137.

Ishaq, S.L., and Wright, A.D. 2012. Insight into the bacterial gut microbiome of the North American moose (Alces alces). BMC Microbiol. 12: 212. doi:10.1186/1471-2180-12-212.

Ishaq, S.L., and Wright, A.D. 2014. High-throughput DNA sequencing of the ruminal 
bacteria from Moose (Alces alces) in Vermont, Alaska, and Norway. Microb. Ecol. 68(2): 185-195. doi:10.1007/s00248-014-0399-0.

Konikoff, T., and Gophna, U. 2016. Oscillospira: a central, enigmatic component of the human gut microbiota. Trends Microbiol. 24(7): 523-524. doi:10.1016/j.tim.2016.02.015.

Krause, D.O., Denman, S.E., Mackie, R.I., Morrison, M., Rae, A.L., Attwood, G.T., and McSweeney, C.S. 2003. Opportunities to improve fiber degradation in the rumen: microbiology, ecology, and genomics. FEMS Microbiol. Rev. 27(5): 663-693. doi:10.1016/S0168-6445(03)00072-X.

Li, Z., Wright, A.-D., Liu, H., Bao, K., Zhang, T., Wang, K., Cui, X., Yang, F., Zhang, Z., and Li, G. 2015. Bacterial community composition and fermentation patterns in the rumen of sika deer (Cervus Nippon) fed three different diets. Microb. Ecol. 69(2): 307-318.

Li, Z., Zhang, Z., Xu, C., Zhao, J., Liu, H., Fan, Z., Yang, F., Wright, A.D., and Li, G. 2014. Bacteria and methanogens differ along the gastrointestinal tract of Chinese roe deer (Capreolus pygargus). PLOS ONE 9(12): e114513. doi:10.1371/journal.pone.0114513.

Li, Z.P., Liu, H.L., Li, G.Y., Bao, K., Wang, K.Y., Xu, C., Yang, Y.F., Yang, F.H., and Wright, A.D. 2013. Molecular diversity of rumen bacterial communities from tannin-rich and fiber-rich forage fed domestic Sika deer (Cervus Nippon) in China. BMC Microbiol. 13(1): 151. doi:10.1186/1471-2180-13-151.

Lozupone, C., Lladser, M.E., Knights, D., Stombaugh, J., and Knight, R. 2011. 
UniFrac: an effective distance metric for microbial community comparison. ISME J. 5(2): 169-172. doi:10.1038/ismej.2010.133.

Mackie, R.I., Aminov, R.I., Hu, W., Klieve, A.V., Ouwerkerk, D., Sundset, M.A., and Kamagata, Y. 2003. Ecology of uncultivated Oscillospira species in the rumen of cattle, sheep, and reindeer as assessed by microscopy and molecular approaches. Appl. Environ. Microbiol. 69(11): 6808-6815. doi:10.1128/AEM.69.11.6808-6815.2003.

Matsui, H., Ogata, K., Tajima, K., Nakamura, M., Nagamine, T., Aminov, R.I., and Benno, Y. 2000. Phenotypic characterization of polysaccharidases produced by four Prevotella type strains. Curr. Microbiol. 41(1): 45-49. doi: $10.1007 / \mathrm{s} 002840010089$.

Moeller, A.H., Peeters, M., Ndjango, J.-B., Li, Y., Hahn, B.H., and Ochman, H. 2013. Sympatric chimpanzees and gorillas harbor convergent gut microbial communities. Genome Res. 23(10): 1715-1720. doi:10.1101/gr.154773.113.

Moon, C.D., Pacheco, D.M., Kelly, W.J., Leahy, S.C., Li, D., Kopečný, J., and Attwood, G.T. 2008. Reclassification of clostridium proteoclasticum as Butyrivibrio proteoclasticus comb. Nov., A butyrate-producing ruminal bacterium. Int. J. Syst. Evol. Microbiol. 58(9): 2041-2045. doi:10.1099/ijs.0.65845-0.

Newbold, C.J., de la Fuente, G., Belanche, A., Ramos-Morales, E., and McEwan, N.R. 2015. The role of ciliate protozoa in the rumen. Front. Microbiol. 6: 1313. doi:10.3389/fmicb.2015.01313. 
Pérez-Barberia, F.J., Elston, D.A., Gordon, I.J., and Illius, A.W. 2004. The evolution of phylogenetic differences in the efficiency of digestion in ruminants. Proc. R. Soc. B Biol. Sci. 271(1543): 1081-1090. doi:10.1098/rspb.2004.2714.

Pope, P.B., Mackenzie, A.K., Gregor, I., Smith, W., Sundset, M.A., McHardy, A.C., Morrison, M., and Eijsink, V.G. 2012. Metagenomics of the Svalbard reindeer rumen microbiome reveals abundance of polysaccharide utilization loci. PLOS ONE 7(6): e38571. doi:10.1371/journal.pone.0038571.

Pope, P.B., Smith, W., Denman, S.E., Tringe, S.G., Barry, K., Hugenholtz, P., McSweeney, C.S., McHardy, A.C., and Morrison, M. 2011. Isolation of Succinivibrionaceae implicated in low methane emissions from Tammar wallabies. Science 333(6042): 646-648. doi:10.1126/science.1205760.

Puniya, A.K., Singh, R., and Kamra, D.N. 2015. Rumen microbiology: from evolution to revolution. Springer India, Private Ltd, India.

Purushe, J., Fouts, D.E., Morrison, M., White, B.A., Mackie, R.I., North American Consortium for Rumen Bacteria, Coutinho, P.M., Henrissat, B., and Nelson, K.E. 2010. Comparative genome analysis of Prevotella ruminicola and Prevotella bryantii: insights into their environmental niche. Microb. Ecol. 60(4): 721-729. doi:10.1007/s00248-010-9692-8.

Qiao, J., Yang, W., and Gao, X. 2006. Natural diet and food habitat use of the Tarim red deer, Cervus elaphus yarkandensis. Chin. Sci. Bull. 51(S1): 147-152. doi:10.1007/s11434-006-8219-7.

Samsudin, A.A., Evans, P.N., Wright, A.D., and Al Jassim, R. 2011. Molecular 
diversity of the foregut bacteria community in the dromedary camel (Camelus dromedarius). $\quad$ Environ. $\quad$ Microbiol. 13(11): 3024-3035. doi:10.1111/j.1462-2920.2011.02579.x.

Smith, C.C., Snowberg, L.K., Gregory Caporaso, J., Knight, R., and Bolnick, D.I. 2015. Dietary input of microbes and host genetic variation shape among-population differences in stickleback gut microbiota. ISME J. 9(11): 2515-2526. doi:10.1038/ismej.2015.64.

Stackebrandt, E., and Hespell, R. 2006. The family Succinivibrionaceae. In The Prokaryotes. Edited by M. Dworkin, S. Falkow, E. Rosenberg, K.-H. Schleifer and E. Stackebrandt. Springer US, New York. pp. 419-429.

Sundset, M.A., Praesteng, K.E., Cann, I.K., Mathiesen, S.D., and Mackie, R.I. 2007. Novel rumen bacterial diversity in two geographically separated sub-species of reindeer. Microb. Ecol. 54(3): 424-438. doi:10.1007/s00248-007-9254-x.

Sylvester, J.T., Karnati, S.K., Dehority, B.A., Morrison, M., Smith, G.L., St-Pierre, N.R., and Firkins, J.L. 2009. Rumen ciliated protozoa decrease generation time and adjust $18 \mathrm{~S}$ ribosomal DNA copies to adapt to decreased transfer interval, starvation, and monensin. J. Dairy Sci. 92(1): 256-269. doi:10.3168/jds.2008-1417.

Van Gylswyk, N. 1995. Succiniclasticum ruminis gen. nov., Sp. nov., A ruminal bacterium converting succinate to propionate as the sole energy-yielding mechanism. Int. J. Syst. Evol. Microbiol. 45(2): 297-300.

Wang, Q., Garrity, G.M., Tiedje, J.M., and Cole, J.R. 2007. Naïve bayesian classifier 
for rapid assignment of rRNA sequences into the new bacterial taxonomy. Appl. Environ. Microbiol. 73(16): 5261-5267. doi:10.1128/AEM.00062-07.

Wright, A.G., and Klieve, A.V. 2011. Does the complexity of the rumen microbial ecology preclude methane mitigation? Anim. Feed Sci. Technol. 166-167: 248-253. doi:10.1016/j.anifeedsci.2011.04.015.

\section{Figure legends}

Figure 1. Rumen bacterial compositions at the phylum (A) and genus (B) levels across the three hosts.

Figure 2. Comparisons of the bacterial communities in the rumen of the cattle, red deer and sheep. Principal coordinate analyses based on unweighted UniFrac distance (A) and weighted UniFrac distance among the groups (B). Significant differences were observed at the genus level across the three hosts $(\mathbf{C}) .{ }^{*} P<0.05, * * P<0.01$, $* * * P<0.001$

Figure 3. Comparison of the concentrations of volatile fatty acids and $\mathrm{NH}_{3}-\mathrm{N}$ in the rumen of the cattle, red deer and sheep. ${ }^{*} P<0.05, * * P<0.01, * * * P<0.001$. 
Table 1. Ingredient composition of the diet fed to the cattle, red deer and sheep.

\begin{tabular}{llc}
\hline Formula & Ingredient & \% (Dry matter) \\
\hline Forage & Reed & 40.00 \\
& Dried poplar leaf & 30.00 \\
Concentrate & Corn starch & 18.63 \\
& Wheat hull & 4.00 \\
& Soybean meal & 4.20 \\
& Bone powder & 0.16 \\
& Salt & 0.50 \\
& Additive & 1.00 \\
& Linseed meal & 1.50 \\
\hline
\end{tabular}


Table 2. Summary of the sequencing data and alpha diversity across the three hosts

\begin{tabular}{|c|c|c|c|c|c|c|}
\hline Samples & Sequences & OTUs & $\begin{array}{l}\text { Good's } \\
\text { coverage }\end{array}$ & Shannon & Simpson & Chaol \\
\hline Cattle1 & 60,076 & 3181 & 0.98 & 8.73 & 0.99 & 3637.19 \\
\hline Cattle2 & 60,066 & 2997 & 0.98 & 8.81 & 0.99 & 3427.09 \\
\hline Cattle3 & 66,689 & 3549 & 0.98 & 9.23 & 0.99 & 4052.88 \\
\hline Red deer1 & 56,787 & 3028 & 0.98 & 8.84 & 0.99 & 3502.01 \\
\hline Red deer2 & 66,412 & 3593 & 0.98 & 9.19 & 0.99 & 4180.43 \\
\hline Red deer3 & 56,937 & 3110 & 0.99 & 9.35 & 0.99 & 3428.90 \\
\hline Sheep1 & 51,348 & 3050 & 0.97 & 7.84 & 0.97 & 5620.82 \\
\hline Sheep2 & 62,229 & 3195 & 0.98 & 8.13 & 0.98 & 3643.49 \\
\hline Sheep3 & 67,674 & 3060 & 0.98 & 7.96 & 0.96 & 3560.85 \\
\hline
\end{tabular}




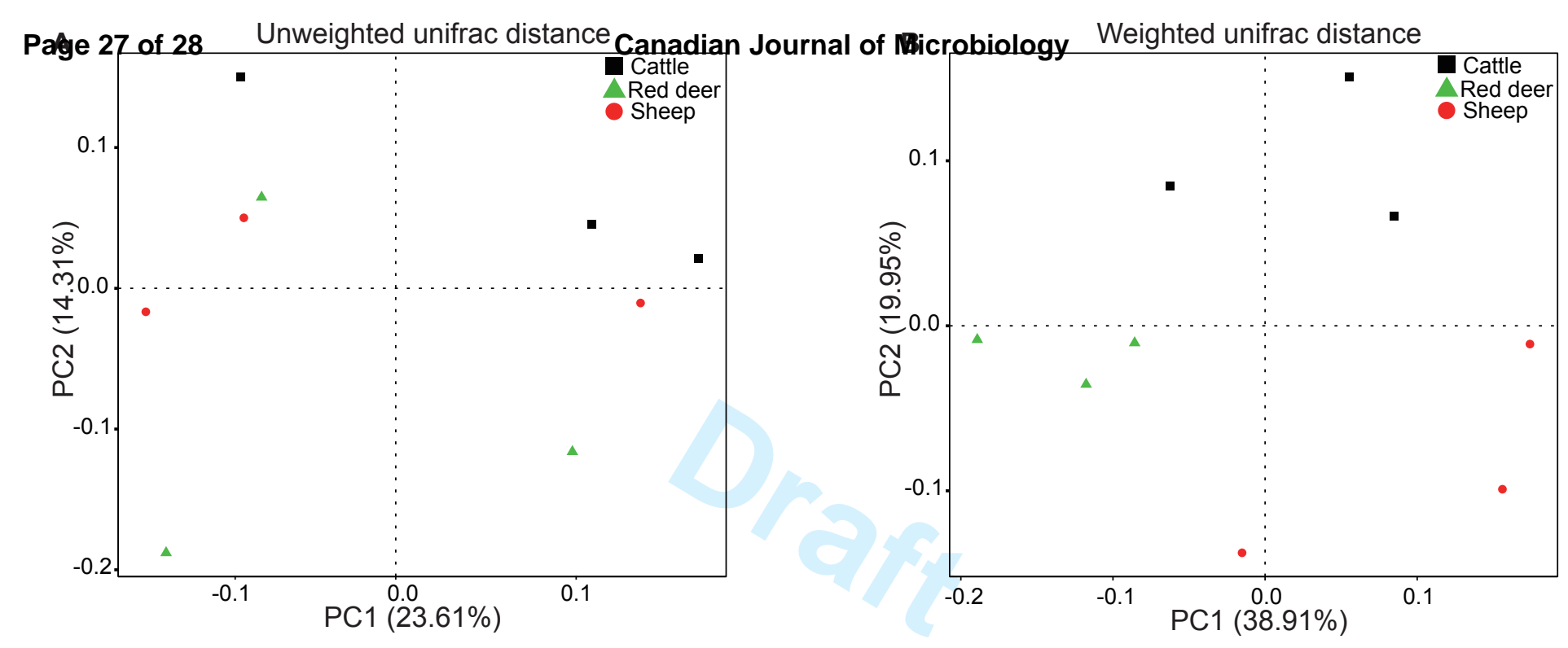

C $\quad \ldots$ Cattle Prevotella
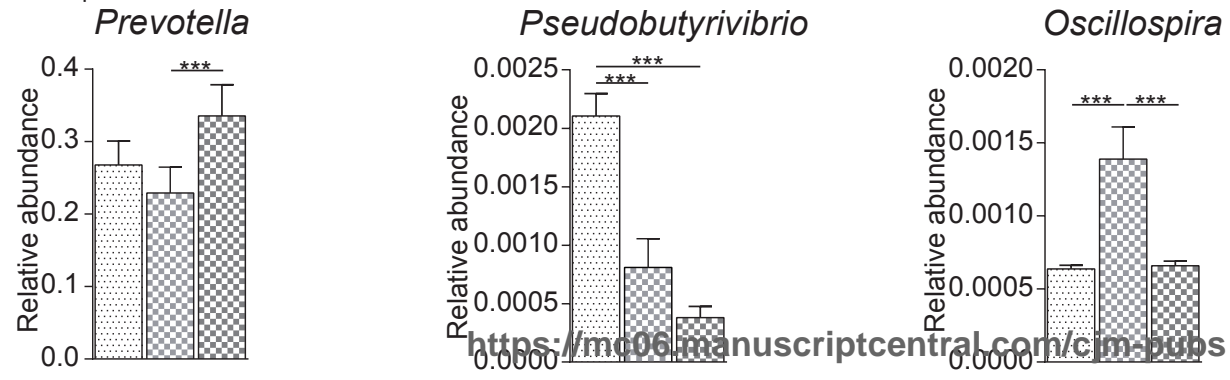

Streptococcus

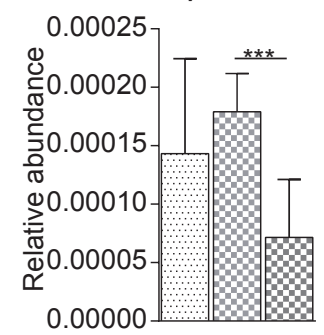



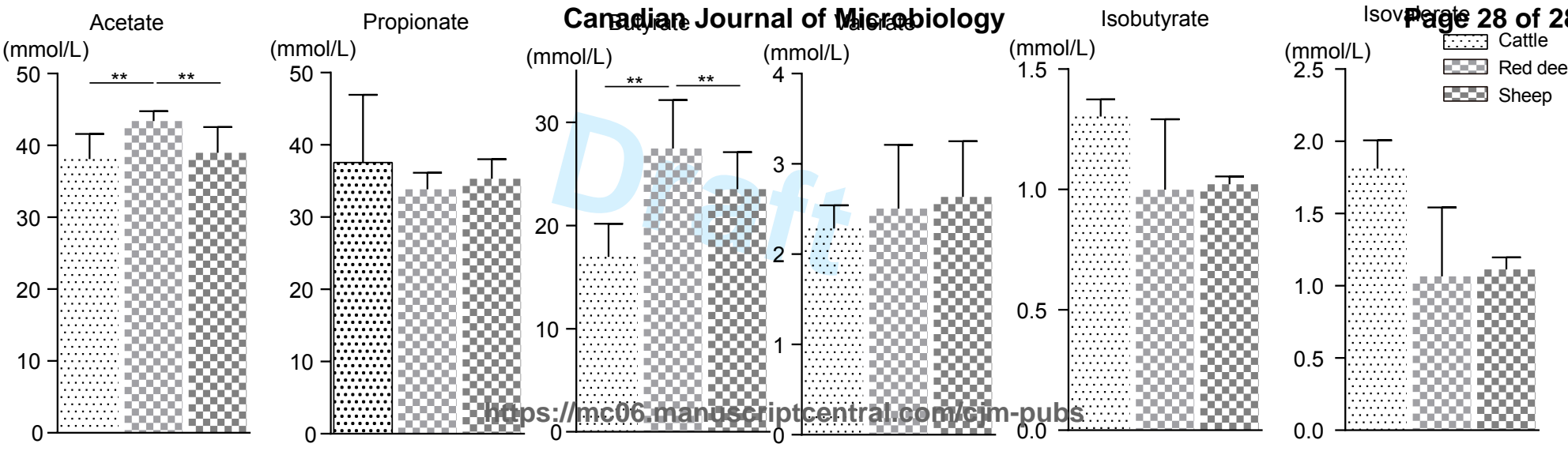